\title{
Modal Analysis of Bridge Structure Using Finite Element Analysis
}

\author{
Alpesh Jain ${ }^{1}$, Dr. J.N. Vyas \\ ${ }^{l}$ (Research Scholar, Civil, MITM Ujjain, India) \\ ${ }_{2}^{2}$ (Professor Civil and Director, MITM Ujjain)
}

\begin{abstract}
The objective of the research study is to model a bridge with four different material using ANSYS software and to perform a modal analysis of bridge problem. For all four materials eight node solid element is selected and meshing is done individually for each modal. The material property of each material is selected as per literature database in ANSYS software. The modal analysis in ANSYS is performed to obtain the natural frequency and mode shapes of bridge to avoid the resonance of the bridge.
\end{abstract}

Keywords: ANSYS , Bridge design, Modal analysis, Mode shape, Natural frequency, Resonance,.

\section{Introduction}

Several studies investigate the dynamic behavior of railway bridges crossed by travelling trains. A simplified formulation was adopted in order to perform a direct analysis of the effects of the parameters involved in the problem. The deformation of the railway bridge subjected to the train load is highly significant, thus it is clear that the dynamic response of the bridge under the moving load must be considered in the process of structural design.

(Melaku.S, Hongsheng Qiu, 2014)

Karoumi (1998) derived approaches for solving the moving load problem of cable-stayed and suspension bridges. This research interests in an efficient finite element program development, to carry out dynamic analyses of bridges. The implemented program is verified by comparing the analysis results with literature and a commercial finite element code. Parametric studies have been performed, investigating the effect of damping, bridge-vehicle interaction, cables vibration, road surface roughness, vehicle speed and tuned mass dampers. It was concluded that road surface roughness has great influence on the dynamic response and should always be considered if possible.

Broquet et al. (2004) describe in a paper the dynamic behavior of deck slabs of concrete road bridge. This research interesting in dynamic analyses of bridges. The finite element method was used to study the local dynamic effects of traffic actions on the deck slabs. Advanced numerical models were described and the results of a parametric study presented. The bridge was represented by a shell element model and the vehicle by lumped masses, assembled in a nonlinear damped system. Important parameters that influence bridge vehicle interaction were taken into account, to investigate characteristic properties of the dynamic behavior of the bridge deck slabs of concrete bridges and to deduce the distribution of dynamic amplification factors throughout the deck slab. The vehicle was excited by irregularities of the road surface, generated by using power spectral density function.

Experimental studies (Wolek 1992) have indicated that present methods of analysis underestimate impact and, thus, the dynamic effect for many structures. Since so many variables play a significant role in the generation and control of the total response, it is essential that bridge designers develop a better understanding of the dynamic behavior of bridge structures and the physical characteristics and parameters that affect response.

\section{Material Properties}

The dynamic material properties for the road-bridge as well as for the adjacent ground are vital information for the study of the road-bridge. Parameters concerning the soil characteristics are taken from the database that was formed during previous studies which were aimed of ensuring adequate vibration levels. By choosing the parameters according to that database it was easier to equate the results with research made previously. The database enclosing material data for the studies also contains information about suitable parameters for concrete and other materials such as asphalt.In Table 2.1 the material parameters which are used in the modelling are displayed. The quantities displayed in Table 2.1 are the materials density $\rho[\mathrm{kg} / \mathrm{m} 3]$, Young's modulus $E[\mathrm{MPa}]$, Poisson's ratio $v[-]$.

Table 1: Material Data

\begin{tabular}{|l|l|l|l|}
\hline Material & Density $\left(\mathrm{Kg} / \mathrm{m}^{3}\right)$ & Young's Modulus $(\mathrm{MPa})$ & Poisson's Ratio \\
\hline Asphalt & 2600 & 5000 & 0.25 \\
\hline Concrete & 2400 & 40000 & 0.20 \\
\hline Clay & 2125 & 476 & 0.48 \\
\hline Bedrock & 2600 & 8809 & 0.40 \\
\hline
\end{tabular}




\section{Modeling Geometry in ANSYS}



Fig.1: Modeling Geometry

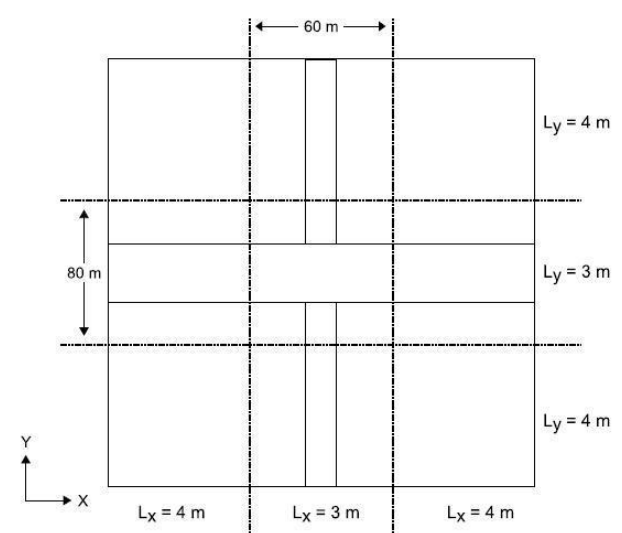

Fig 2: Element length Lx and Ly in the XY-Plan

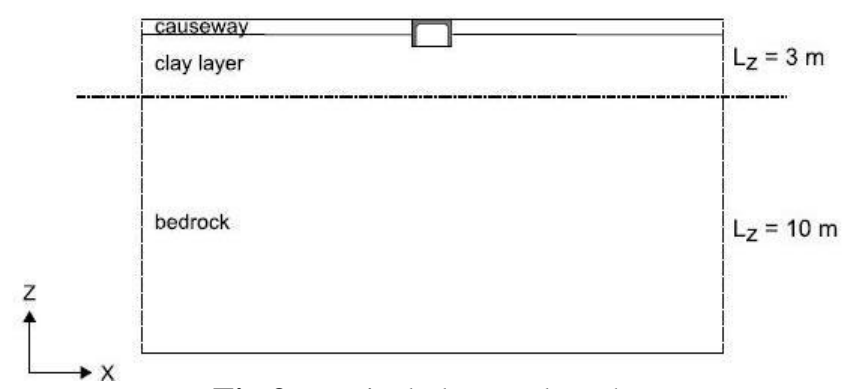

Fig 3: Vertical element length Lz



Fig 4: ANSYS model of bridg

The complete mesh for the whole model was dominated to the number and volume by the Solid 185 element, which is a fully integrated isoparametric element in 3D of second order with 20 nodes. The outer boundaries are modeled with the Solid186 element which is an infinite element in 3D with 12 nodes and 
reduced integration. A problem that may arise when using infinite elements such as Solid186 is zero energy modes since the infinite boundaries does not provide any real boundary condition in terms of prescribed displacement. This is the explanation why the fully integrated element Solid185 had to be chosen instead of the version with reduced integration Solid183.

\section{Modal Analysis of Bridge Structure}

Table below is representing twelve natural frequencies of bridge. The readings are acquired from modal analysis with ANSYS.- First four frequencies are very small and after 12th natural frequency torsional mode obtained.

Table 2: Natural frequency of bridge obtained by analysis

\begin{tabular}{|l|l|}
\hline S. No. & Natural Frequency \\
\hline 1 & $0.11223 \mathrm{E}-04$ \\
\hline 2 & $0.35764 \mathrm{E}-04$ \\
\hline 3 & $0.64400 \mathrm{E}-04$ \\
\hline 4 & $0.10850 \mathrm{E}-03$ \\
\hline 5 & 6.1893 \\
\hline 6 & 9.4231 \\
\hline 7 & 13.995 \\
\hline 8 & 17.043 \\
\hline 9 & 20.090 \\
\hline 10 & 22.916 \\
\hline 11 & 32.054 \\
\hline 12 & 33.203 \\
\hline
\end{tabular}

\section{Results}

The graph shows natural frequencies.

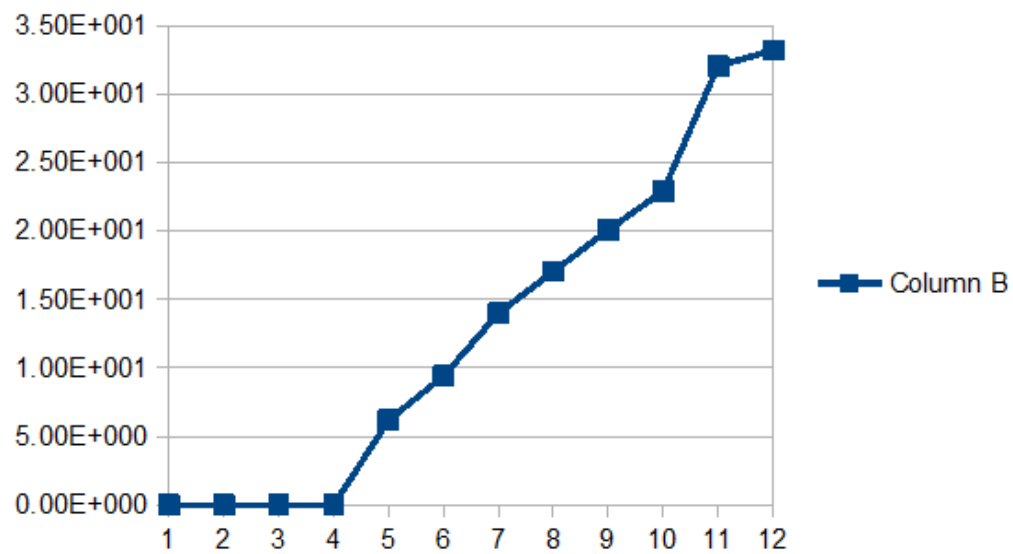

Fig 5: Graph representing natural frequency of bridge

Mode shapes
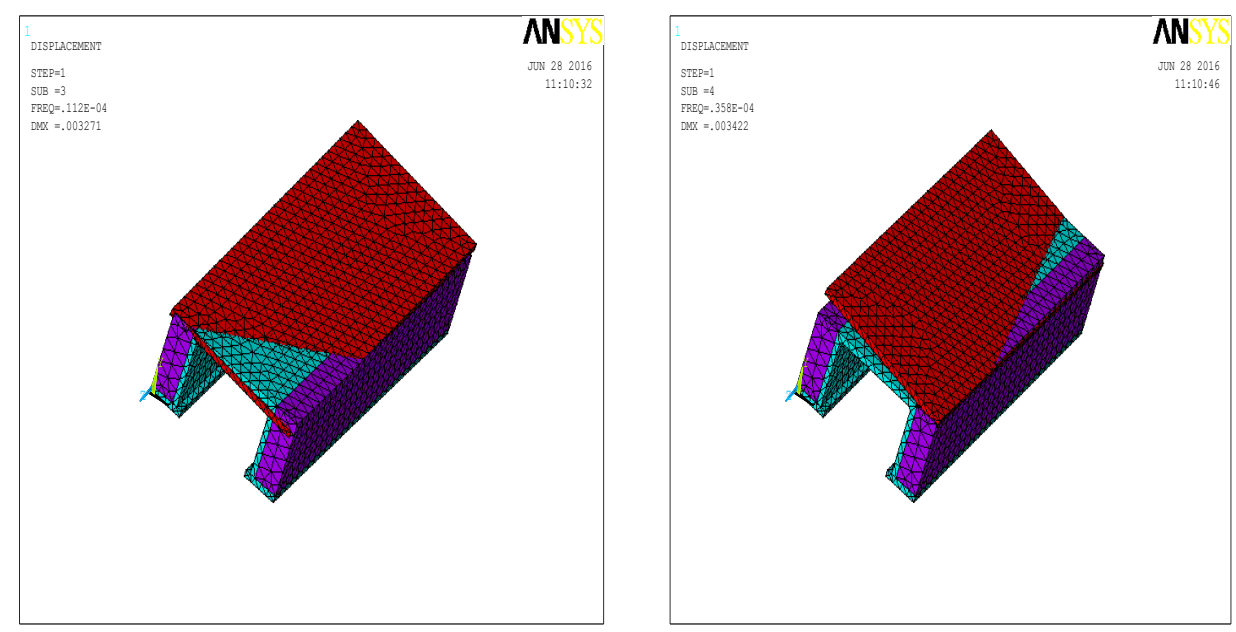

Fig 6: Mode shape I and II 

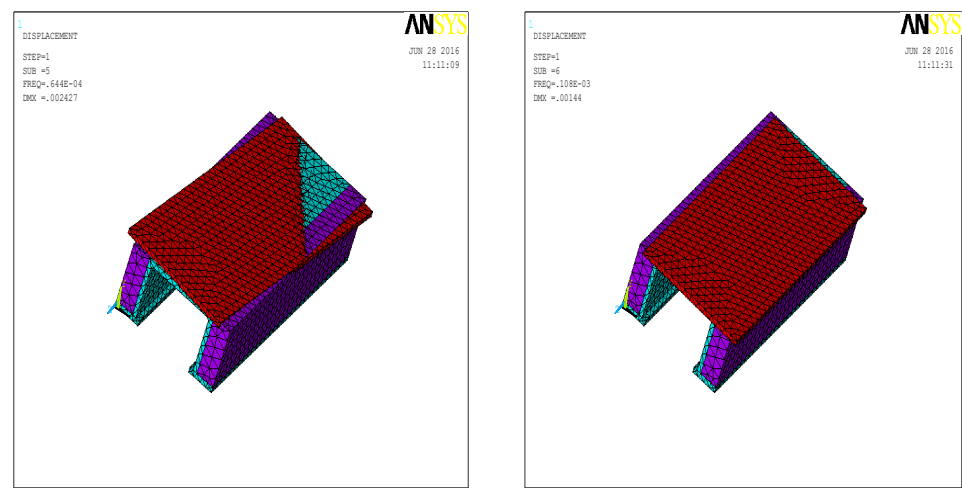

Fig 7: Mode shape III and IV
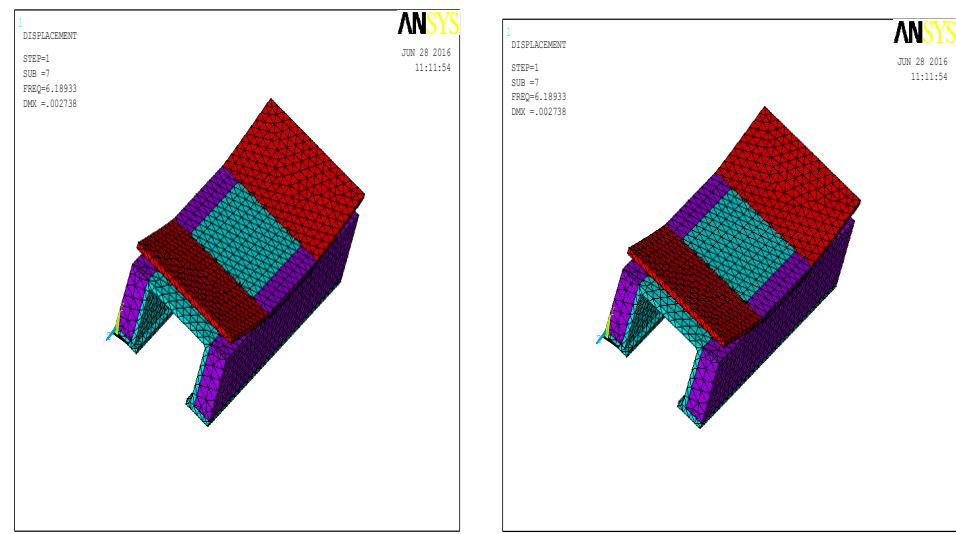

Fig 8: Mode shape V and VI


Fig 9: Mode shape VII and VIII
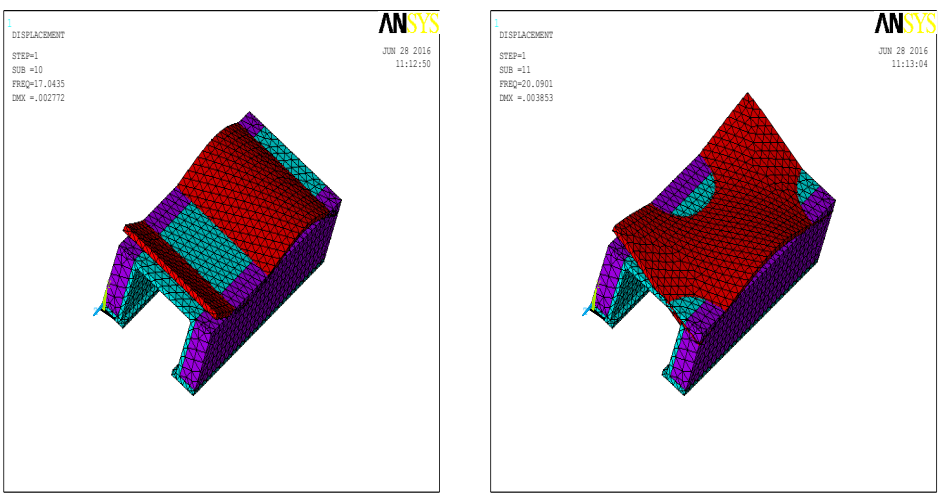

Fig 9: Mode shape IX and X 


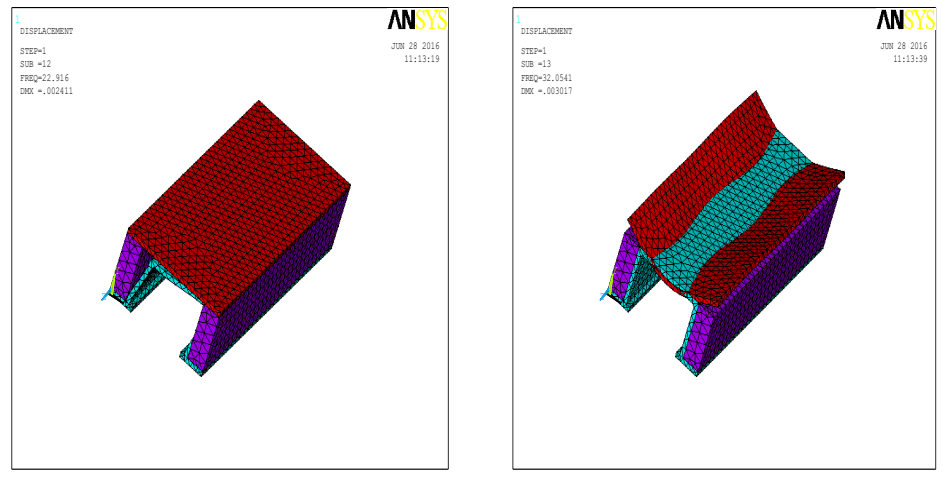

Fig10: Mode shape XI and XII


Fig 11: Mode shape XIII and XIV

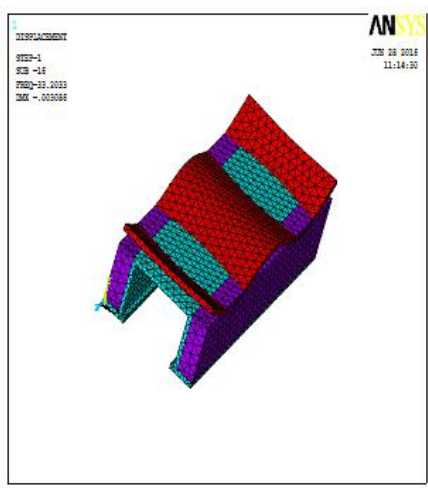

Fig 12: Mode shape XV

\section{Conclusion and Future Scope}

The advantage of the research approach in this paper is to save time, money and most importantly user life using simulation FEA software analysis. We can easily define various material properties with FEA software, and the modal analysis behaves Like actual bridge and the simulation results are quite close to exact solution. In present paper, the result is indicating various natural frequencies, it is concluded that that the bridge is not to be utilized at acquired frequencies which are equal to natural frequency at applied loads. If it is used at natural frequencies, resonances will occur and bridge may damage or fail. The future scope includes transient analysis and harmonic analysis of bridge, also the deflection of the bridge withtime can be obtained with FEA software approach.

\section{References}

[1]. Broquet, C., Bailey, S.F., Fafard, M. And Brühwiler, E., (2004), Dynamic Behaviour of Deck Slabs of Concrete Road Bridges, Journal of Bridge Engineering, Vol. 9, No. 2, ISSN 10084-0702/2004/2-137.

[2]. KAROUMI, R., (1998), Response of Cable-Stayed and Suspension Bridges to Moving Vehicles Analysis methods and practical modelling techniques,Doctoral Thesis, Royal Institute of Technology, Stockholm, ISSN 1103-4270.

[3]. Melaku.S, Hongsheng Qiu, Transient Dynamic Analysis of Simple Railway Bridge under Train Moving Load, 2014 International Conference on Civil Engineering, Energy and Environment

[4]. Bangash, M. Y. H., Concrete and Concrete Structures: Numerical Modeling and Applications, Elsevier Science Publishers Ltd., London, England, 1989. 